\title{
MENINGKATKAN KEMAMPUAN BERKOMUNIKASI ANAK MELALUI METODE CERITA BERGAMBAR PADA PAUD KELOMPOK B
}

\author{
Abdul Syukur \\ Meo Melianus Tefanai \\ Program Studi Pendidikan Luar Sekolah Jurusan Ilmu Pendidikan \\ Fakultas Keguruan dan Ilmu Pendidikan \\ Universitas Nusa Cendana Kupang \\ email : abdulsyukur376@gmail.com
}

\begin{abstract}
Improving Children's Communication Skills through Pictorial Stories Applied to Early Childhood Education Program Group B. The aim of this research is to improve the communication skills of children through the method of pictorial stories applied to group B ECD Gemilang in the District of Maulafa, Kota Kupang. This is a type of Classroom Action Research that consists of four stages in each cycle, they are: planning, implementation, observation and reflection. The main focus of this research is to improve children's skills and ability to communicate through this pictorial story method. Nineteen children have been included in this study and the data has been collected through observation and tests. The results show that the average score of precycle is $37.57 \%$, the one of the first cycle is $57.89 \%$ and $100 \%$ is the average score achieved in the second cycle. Looking at these results, it can be stated that using pictorial stories in a learning process can improve children's communication skills and ability.
\end{abstract}

Keywords : Media images, improve communication skills.

Abstrak : Meningkatkan Kemampuan Berkomunikasi Anak Melalui Metode Cerita Bergambar Pada PAUD Kelompok B. Tujuan penelitian ini untuk untuk meningkatkan kemampuan berkomunikasi anak melalui metode cerita bergambar di kelompok B PAUD Gemilang Kelurahan Maulafa Kota Kupang. Jenis penelitian ini adalah Penelitian Tindakan Kelas yang terdiri dari 4 tahap dalam setiap siklus yaitu perencanaan, pelaksanaan, observasi dan refleksi. Fokus penelitian ini adalah meningkatkan kemampuan berkomunikasi anak melalui metode cerita bergambar pada PAUD kelompok B. Setting penelitian ini adalah anak-anak di PAUD Gemilang. Objek penelitian ini berjumlah 19 anak. Pengumpulan data melalui observasi dan tes hasil belajar. Dari perhitungan terhadap data tersebut diperoleh nilai rata-rata prasiklus $37,57 \%$, siklus I sebesar 57, 89\% dan Siklus II 100\%, maka secara umum dapat digolongkan bahwa pembelajaran menggunakann metode cerita bergambar dapat meningkatkan kemampuan berkomunikasi anak.

Kata Kunci : Media gambar, meningkatkan, kemampuan berkomunikasi 
Usia awal kehidupan anak yang sangat menentukan dalam perkembangan kecerdasannya adalah pada usia 0-8 tahun atau yang sering disebut dengan masa golden age (Suyanto, 2005: 6). Pada masa ini anak akan berkembang sangat kritis dan cepat menyerap apapun yang anak dapat dari lingkungannya. Pengalaman yang didapat oleh anak akan berpengaruh dan menentukan kemampuan anak dalam menghadapi tantangan hidup yang akan datang, maka dibangunlah kesadaran akan pentingnya pendidikan anak usia dini yang dimulai pada usia 0-8 tahun dengan tujuan untuk mempersiapkan mereka menerima pendidikan ke jenjang yang lebih tinggi.

Pendidikan anak usia dini (PAUD) adalah suatu upaya pembinaan yang ditujukan kepada anak sejak lahir sampai dengan usia enam tahun, yang dilakukan melalui pemberian rangsangan pendidikan untuk membantu pertumbuhan dan perkembangan jasmani dan rohani, agar anak memiliki kesiapan dalam memasuki pendidikan lebih lanjut (UU Nomor 20 Tahun 2003). Pendidikan anak usia dini bertujuan untuk mengembangkan semua aspek perkembangan yang dimiliki anak untuk memunculkan potensi secara optimal. Aspek perkembangan tersebut meliputi aspek nilai agama dan moral, aspek sosial emosional, aspek kognitif, aspek bahasa, dan aspek fisik motorik. Salah satu aspek perkembangan anak usia dini adalah bahasa.

Pendidikan anak usia dini merupakan salah satu bentuk pendidikan prasekolah yang ada di jalur pendidikan sekolah. Kurikulum yang dikembangkan berdasarkan karakteristik anak dan dalam rangka mengembangkan seluruh potensi anak. Struktur program kegiatan pendidikan anak usia dini mencakup bidang pengembangan pembentukan perilaku dan bidang pengembangan kemampuan dasar melalui kegiatan bermain dan pembiasaan. Lingkup pengembangan meliputi: (1) Nilainilai agama dan moral (2) Fisik (3) Kognitif (4) Bahasa (5) Sosial emosional. Kegiatan pengembangan suatu aspek dilakukan secara terpadu dengan aspek yang lain menggunakan pendekatan tematik. Sebagai alat komunikasi, bahasa merupakan sarana yang sangat penting dalam kehidupan anak. Selain itu, bahasa juga merupakan alat untuk menyatakan pikiran dan perasaan kepada orang lain yang sekaligus juga berfungsi untuk memahami pikiran dan perasaan orang lain. Perkembangan bahasa anak PAUD bertambah terus setelah masuk sekolah, baik jumlah kosakata maupun perluasan kalimat. Ketika usia 5 tahun, mereka telah menghimpun kurang lebih 8000 kosakata, disamping telah menguasai hampir semua bentuk dasar tata bahasa. Mereka dapat membuat pertanyaan, kalimat negatif, kalimat tunggal, kalimat majemuk (Hidayati, 2014: 2).

Berkaitan dengan kemampuan berkomunikasi anak, terdapat beberapa faktor yang dapat mempengaruhi perkembangan bahasa, yaitu sebagai berikut : faktor kesehatan, intelegensi, status sosial ekonomi keluarga, jenis kelamin, dan lingkungan. Kemampuan anak usia 4 - 5 tahun untuk lingkup perkembangan menerima bahasa, salah satunya diharapkan siswa mampu memahami cerita yang dibacakan. Sedangkan dalam mengungkapkan bahasa, salah satunya yaitu siswa mampu menceritakan kembali cerita atau dongeng yang pernah didengar (Hidayati, 2014: 3).

Media gambar adalah media yang merupakan reproduksi bentuk asli dalam dua dimensi yang berupa foto atau lukisan (Rolina, 2010: 39). Penggunaan media gambar dalam pembelajaran mempunyai beberapa kelebihan yaitu bersifat konkret, dapat mengatasi batasan ruang dan waktu, media gambar dapat mengatasi keterbatasan pengamatan kita, dapat memperjelas suatu masalah, dan harga lebih murah dan gampang didapat (Sadiman, 2009: 29-31).

Kenyataan yang terjadi di PAUD Gemilang Kota Kupang khususnya kelas B, sebagian besar anak masih kesulitan dalam menyampaikan perasaannya kepada guru, atau menjawab pertanyaan dari guru dengan kata yang kurang tepat. Ini terlihat pada saat anak mencoba menceritakan pengalaman di depan kelas, anak-anak masih bingung dengan katakata yangakan diucapkan, sehingga anak menjadi kurang percaya diri bila berbicara di depan teman-temannya. Kebingungan atau ketidak mampuan anak dalam berbicara disebabkan karena bahasa yang digunakan campur-campur antara bahasa Indonesia dengan bahasa sehari hari. 
Keterbatasan anak dalam berkomunikasi di kelas dikarenakan metode yang digunakan guru masih belum tepat dan belum sesuai dalam menstimulasi perkembangan bahasa anak. Guru lebih sering menggunakan metode bercakap-cakap tanpa menggunakan media. Guru pernah mencoba menggunakan media berupa gambar di papan tulis tetapi tidak ada peningkatan dalam perkembangan berbicara anak, karena ternyata anak masih belum lancar berbicara sehingga kesulitan dalam mengungkapkan apa yang anak rasakan.

Berdasarkan latar belakang di atas maka judul yang diangkat adalah : "Meningkatan Kemampuan Berkomunikasi Anak Melalui Metode Cerita Bergambar pada PAUD Kelompok B".

\section{Kemampuan Berkomunikasi Pada Anak Usia Dini}

Hurlock (1978: 176), mengemukakan bahwa bicara adalah bentuk bahasa yang menggunakan artikulasi atau kata-kata yang digunakan untuk menyampaikan maksud. Pendapat serupa juga diungkapkan oleh Tarigan (dalam Suhartono, 2005: 20), bahwa bicara adalah kemampuan mengucapkan bunyi-bunyi artikulasi atau kata-kata untuk mengekspresikan, menyatakan serta menyampaikan pikiran, gagasan, dan perasaan. Metode Bercerita berarti penyampaian cerita dengan cara bertutur. Yang membedakan antara bercerita dengan metode penyampaian cerita lain adalah lebih menonjol aspek teknis penceritaan lainnya. Sebagaimana phantomin yang lebih menonjolkan gerak dan mimik, operet yang lebih menonjolkan musik dan nyanyian, puisi dan deklamasi yang lebih menonjolkan syair, sandiwara yang lebih menonjol pada permainan peran oleh para pelakunya, atau monolog (teater tunggal) yang mengoptimalkan semuanya. Jadi tegasnya metode bercerita lebih menonjolkan penuturan lisan materi cerita dibandingkan aspek teknis yang lainnya.

\section{METODE}

Jenis penelitian yang digunakan yaitu penelitian tindakan kelas. Penelitian tindakan kelas merupakan suatu pencermatan terhadap kegiatan yang sengaja dimunculkan, dan terjadi dalam sebuah kelas (Arikunto, 2006:91). Penelitian ini pada dasarnya merupakan proses investigasi terkendali untuk menemukan dan memecahkan masalah pembelajaran di kelas, proses pemecahan masalah tersebut dilakukan secara bersiklus dengan tujuan untuk meningkatkan kualitas pembelajaran dan hasil pembelajaran di kelas tertentu.

Lokasi penelitian ini adalah PAUD Gemilang Kota Kupang sedangkan waktu penelitian adalah tiga bulan, pada awal bulan Agustus sampai akhir Oktober. Indikator ketercapaiannya adalah siswa mampu mengingat dan menceritakan kembali cerita yang sudah disampaikan oleh guru.

Subjek penelitian adalah siswa PAUD Gemilang kelompok B yang berjumlah 19 orang yang terdiri dari 10 siswa laki-laki dan 9 siswa perempuan.

\section{Prosedur Penelitian}

Prosedur yang digunakan dalam penelitian tindakan kelas adalah dalam bentuk rangkaian siklus yang terdiri dari beberapa tahapan yaitu perencanaan, pelaksanaan, pengamatan dan refleksi. Siklus ini dipakai secara berulang-ulang sesuai dengan kebutuhan dari penelitian. Dalam satu siklus pembelajaran terdiri dari dua kali tatap muka. Tiap siklus dilaksanakan sesuai dengan perubahan yang dicapai. Penelitian ini terdiri dari dua silkus dimana setiap siklus terdiri atas empat tahapan kegiatan.

\section{Teknik Pengumpulan Data}

\section{Observasi}

Teknik pengumpulan data dalam penelitian adalah observasi langsung dimana kegiatan ini digunakan untuk mengamati anak pada saat kegiatan belajar mengajar dengan kegiatan menceritakan kembali cerita yang sudah diceritakan oleh guru. 
Teknik ini merupakan cara pengumpulan data berupa hasil tes belajar siswa, dimana dalam mengumpulan data perlu diadakan tes hasil belajar terlebih dahulu baik secara lisan maupun tertulis. Dalam penelitian ini yang dinilai adalah kemampuan anak dalam berkomunikasi, maka dari itu peneliti menggunakan tes lisan dengan cara meminta anak menceritakan kembali cerita yang telah disampaikan oleh peneliti.

\section{Desain Penelitian}

Keadaan awal tentang anak di PAUD Gemilang yang peneliti amati mengenai kemampuan berkomunikasi anak yang masih sangat rendah, ada yang sudah mampu berkomunikasi dengan baik dan ada pula yang belum mampu berkomunikasi dengan baik. Hal ini disebabkan karena guru belum menemukan metode yang tepat dalam proses belajar mengajar sehingga belum tercipta suasana belajar yang kondusif yang mampu melibatkan anak belajar secara aktif.

\section{Deskripsi Siklus I}

1 Perencanaan

Dalam tahap perencanaan peneliti mempersiapkan rencana pelaksanaan pembelajaran harian (RPPH) dan media yang akan digunakan dalam proses pembelajaran berupa buku cerita bergambar.

\section{Pelaksanaan}

Dalam tahap pelaksanaan peneliti melakukan proses belajar dan peneliti berperan langsung sebagai guru. Langkah-langkah pembelajaran adalah:

a. Peneliti memulai kegiatan pembelajaran dengan mengajak anak untuk berdoa bersama

b. Peneliti mengajak anak untuk bernyayi bersama beberapa lagu yang berkaitan dengan topik/materi yang akan diajarkan

c. Peneliti meyampaikan materi yang akan dipelajari d. Peneliti mulai bercerita menggunakan buku cerita bergambar yang telah dipersiapkan

e. Peneliti meminta anak untuk menceritakan kembali apa yang telah diceritakan di depan kelas menggunakan media yang dipersiapkan

f. Peneliti mengajak anak untuk menutup kegiatan pembelajaran dengan berdoa bersama.

\section{Refleksi Siklus I}

Berdasarkan tahap pelaksanaan dan langkah-langkah penelitian maka peneliti, guru dan observer melakukan refleksi untuk mengetahui kekurangankekurangan yang perlu dibenahi sebagai bahan perbaikan bagi peneliti dalam pelaksanaan siklus II.

\section{Deskripsi Siklus II}

Siklus II dilaksanakan berdasarkan hasil refleksi siklus I. Apabila dalam siklus I ketuntasan belajar siswa belum mencapai kriteria ketuntasan minimum (KKM) maka siklus II perlu dilakukan agar anak dapat mencapai kriteria ketuntasan minimum (KKM) namun apabila dalam siklus I anak sudah dapat mencapai KKM maka siklus II dilakukan sebagai penguatan. Siklus II juga dilakukan dalam tiga tahap seperti pada siklus I.

1 Perencanaan

Dalam tahap perencanaan pada siklus II peneliti melakukan revisi rencana pelaksanaan pembelajaran harian dan menyiapkan media yang akan digunakan dalam pembelajaran.

\section{Pelaksanaan}

Tahap pelaksanaan pada siklus II tidak jauh berbeda dengan pelaksanaan pada siklus I, namun pada siklus II peneliti lebih fokus pada kekurangankekurangan yang telah direfleksi pada siklus I.

\section{$3 \quad$ Refleksi Siklus II}

Dari hasil pembelajaran yang telah dilakukan, peneliti, observer dan guru melakukan evaluasi bersama untuk 
melihat hasil tes dan keefektifan proses pembelajaran.

\section{Teknik Analisis Data}

Data Observasi, maupun data tes dikumpulkan dan dianalisis untuk mengetahui nilai rata-rata kelas dan persentase ketuntasan yang dicapai (Arikunto, 1993:33). Maka untuk mengetahui hasil dari rata-rata kelas dan ketuntasan nilai secara klasikal dapat digunakan Rumus sebagai berikut:

Nilai Rata-rata kelas diperoleh dari:

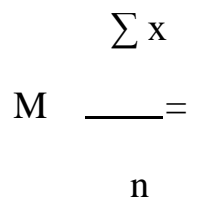

Keterangan :

$\mathrm{M}=$ rata-rata kelas

$\mathrm{n}=$ jumlah siswa

$\sum \mathrm{x}=$ jumlah nilai yang diperoleh siswa

Nilai ketuntasan data diperoleh dari:

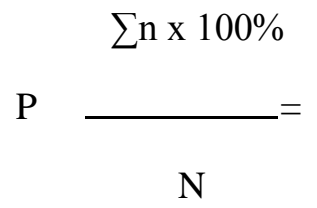

Keterangan :

$\mathrm{P}=$ Persentase ketuntasan belajar

$\mathrm{N}=$ Jumlah siswa

$\sum \mathrm{n}=$ Jumlah siswa yang tuntas belajar

\section{Indikator Keberhasilan}

Untuk menentukan keberhasilan dalam penelitian maka perlu adanya indikator keberhasilan. Dimana pada penelitian ini kriteria ketuntasan pembelajaran sebesar $70 \%$ maka penelitian dianggap berhasil. Dikatakan tuntas jika siswa telah mencapai Kriteria Ketuntasan Minimal yang ditentukan yaitu 70 .

\section{Deskripsi Hasil Data Pra Penelitian}

Keadaan awal tentang anak di PAUD Gemilang yang sudah amati dapat dilihat melalui tabel 1 :

Tabel 1

Hasil Belajar Pra Siklus

\begin{tabular}{|c|l|c|c|}
\hline No & \multicolumn{1}{|c|}{ Nama Siswa } & Nilai & Ket. \\
\hline 1 & Asriani Ngadas (AN) & 70 & T \\
\hline 2 & Alfianus Bana (AB) & 60 & BT \\
\hline 3 & Bolifardo Nifu (BN) & 60 & BT \\
\hline 4 & Basilius Usboko (BU) & 60 & BT \\
\hline 5 & Diky Moy (DM) & 70 & T \\
\hline 6 & Eyang Sau (ES) & 70 & T \\
\hline 7 & Grestia Mone (GM) & 65 & BT \\
\hline 8 & Maria Yoniur (MY) & 70 & T \\
\hline 9 & Meliana Solo (MS) & 70 & T \\
\hline 10 & Stevania Boimau (SB) & 60 & BT \\
\hline 11 & Sitria Amnifu (SA) & 65 & BT \\
\hline 12 & Vino Sanam (VS) & 55 & BT \\
\hline 13 & Yeni Faot (YF) & 70 & T \\
\hline 14 & Yuliana Nahak (YN) & 60 & BT \\
\hline 15 & Faldi Benu (FB) & 50 & BT \\
\hline 16 & Sandro Boimau (SB) & 55 & BT \\
\hline 17 & Andi Henuk (AH) & 65 & BT \\
\hline 18 & Diven Poli (DP) & 70 & T \\
\hline 19 & $\begin{array}{l}\text { Egidius } \\
\text { Nakamnanu (EN) }\end{array}$ & 70 & T \\
\hline & Jumlah & 53,63 & $\begin{array}{c}\text { Benca } \\
\text { pai } \\
\text { KKM }\end{array}$ \\
\hline & Rata - rata & & \\
\hline & & & \\
\hline
\end{tabular}

Keterangan :

$\mathrm{T}=$ Tuntas $\quad \mathrm{BT}=$ Belum Tuntas

Berdasarkan olahan peneliti pada tabel pra siklus menunjukan kemampuan berkomunikasi anak masih rendah atau belum mencapai KKM yakni dari jumlah siswa 19 anak, yang dikatakan tuntas 8 anak, sedangkan 11 anak belum tuntas.

observasi olahan yang menunjukan kemampuan berkomunikasi anak di PAUD Gemilang Kelurahan Maulafa kelompok B, dari 19 anak hanya 8 anak yang tuntas berkomunikasi benar dalam proses belajar mengajar, sehingga ini menjadi alasan untuk peneliti melakukan penelitian tindakan kelas. 
Tabel 2

Hasil Observai Pra Siklus

\begin{tabular}{|c|c|c|c|c|c|c|c|c|c|c|c|c|}
\hline \multirow[t]{2}{*}{$\begin{array}{l}\mathrm{Na} \\
\mathrm{ma}\end{array}$} & \multicolumn{3}{|c|}{$\begin{array}{c}\text { Bicara } \\
\text { Menggu } \\
\text { nakan } \\
\text { Artikul } \\
\text { asi } \\
\text { Yang } \\
\text { Jelas }\end{array}$} & \multicolumn{3}{|c|}{$\begin{array}{c}\text { Bicara } \\
\text { Menggu } \\
\text { nakan } \\
\text { Intonasi } \\
\text { Yang } \\
\text { Tepat }\end{array}$} & \multicolumn{3}{|c|}{$\begin{array}{c}\text { Bicara } \\
\text { Menggu } \\
\text { nakan } \\
\text { Mimik } \\
\text { Yang } \\
\text { Benar }\end{array}$} & \multirow[t]{2}{*}{ Skor } & \multicolumn{2}{|c|}{ Ket } \\
\hline & 3 & 2 & 1 & 3 & 2 & 1 & 3 & 2 & 1 & & $\mathbf{T}$ & BT \\
\hline AN & & $\sqrt{ }$ & & & $\sqrt{1}$ & & & $\sqrt{1}$ & & 70 & $\sqrt{ }$ & \\
\hline $\mathrm{AB}$ & & $\sqrt{ }$ & & & & $\sqrt{ }$ & & & $\sqrt{ }$ & 60 & & $\sqrt{ }$ \\
\hline $\mathrm{BN}$ & & $\sqrt{ }$ & & & & T & & & $\sqrt{ }$ & 60 & & $\sqrt{ }$ \\
\hline $\mathrm{BU}$ & & $\sqrt{ }$ & & & & V & & & $\sqrt{ }$ & 60 & & $\sqrt{ }$ \\
\hline DM & $\sqrt{ }$ & & & & $\sqrt{ }$ & & $\sqrt{1}$ & & & 70 & $\sqrt{1}$ & \\
\hline ES & $\sqrt{ }$ & . & & $\sqrt{1}$ & & & & $\sqrt{ }$ & & 70 & $\sqrt{ }$ & \\
\hline GM & & $\sqrt{ }$ & & & $\sqrt{1}$ & & & $\sqrt{ }$ & & 65 & & $\sqrt{ }$ \\
\hline MY & $\sqrt{ }$ & & & $\sqrt{ }$ & & & & $\sqrt{ }$ & & 70 & $\sqrt{ }$ & \\
\hline MS & $\sqrt{ }$ & & & $\sqrt{ }$ & & & & $\sqrt{ }$ & & 70 & $\sqrt{ }$ & \\
\hline SB & & $\sqrt{ }$ & & & $\sqrt{ }$ & & & & $\sqrt{ }$ & 60 & & $\sqrt{ }$ \\
\hline SA & & $\sqrt{ }$ & & & & $\sqrt{ }$ & & $\sqrt{ }$ & & 65 & & $\sqrt{ }$ \\
\hline $\mathrm{VS}$ & & & $\sqrt{ }$ & & $\sqrt{ }$ & & & & $\sqrt{ }$ & 55 & & $\sqrt{ }$ \\
\hline YF & & $\sqrt{ }$ & & & $\sqrt{1}$ & & & $\sqrt{ }$ & & 70 & $\sqrt{1}$ & \\
\hline YN & & & $\sqrt{ }$ & & $\sqrt{1}$ & & & & $\sqrt{ }$ & 60 & & $\sqrt{ }$ \\
\hline FB & & & $\sqrt{ }$ & & & $\sqrt{ }$ & & & $\sqrt{ }$ & 50 & & $\sqrt{ }$ \\
\hline SB & & & $\sqrt{ }$ & & $\sqrt{ }$ & & & & $\sqrt{ }$ & 55 & & $\sqrt{ }$ \\
\hline $\mathrm{AH}$ & & $\sqrt{ }$ & & & $\sqrt{1}$ & & & & $\sqrt{ }$ & 65 & & $\sqrt{ }$ \\
\hline DP & & $\sqrt{ }$ & & & $\sqrt{1}$ & & & $\sqrt{ }$ & & 70 & $\sqrt{ }$ & \\
\hline EN & $\sqrt{ }$ & & & $\sqrt{1}$ & & & & $\sqrt{1}$ & & 70 & $\sqrt{ }$ & \\
\hline \multicolumn{10}{|c|}{ Jumlah } & 1.080 & 8 & 11 \\
\hline & & & & ta-1 & & & & & & & 63 & \\
\hline
\end{tabular}

Keterangan tabel :

3 = Sangat Baik 2 = Cukup Baik 1= Kurang Baik

$\mathrm{T}=$ Tuntas $\mathrm{BT}=$ Belum Tuntas

\section{Deskripsi Hasil Data Penelitian Siklus I}

Penelitian siklus 1 dimulai dari perencanaan, pelaksanaan, observasi dan refleksi.

\section{Perencanaan}

Berdasarkan hasil refleksi pada siklus I maka peneliti lebih memotivasi anak yang belum tuntas untuk lebih bersungguh-sungguh mengikuti kegiatan pembelajaran pada siklus I ini.

\section{Pelaksanaan}

Pada tahap ini kegiatan pembelajaran melalui 3 kegiatan :
Kegiatan Awal : anak-anak berbaris di halaman sebelum masuk kelas, setelah masuk ke dalam kelas, guru meminta salah satu anak untuk memberi salam dan berdoa. Kemudian guru memanggil masing-masing anak dan mengisi daftar absensi anak. Guru mengajak anak bernyanyi sesuai tema yang akan diajarkan. Guru memberikan kesempatan kepada anak untuk bertanya.

Kegiatan Inti : kegiatan yang pertama dilakukan guru kurang lebih sama dengan pertemuan-pertemuan sebelumnya ialah menyiapkan buku cerita bergambar, setelah itu guru mengemukakan tema yang akan diajarkan yaitu tema alam semesta dan mengemukakan tujuan pembelajaran yang akan dicapai yaitu meningkatkan kemampuan berkomonikasi anak, setelah itu guru memperlihatkan buku gambar yang mempunyai gambar seperti matahari, bintang, bulan dan awan, kemudian anak diberikan kesempatan untuk bertanya da selanjutnya guru menceritakan kepada anak sesuai gambar yang ada. Setelah menceritakan, setiap anak diminta untuk menceritakan kembali apa yang disampaikan guru ataupun menceritakan pengalaman anak sesuai gambar yang dilihat.

Kegiatan Penutup : guru mengadakan tanya jawab tentang kegiatan yang telah dilakukan tadi, anak menyanyikan lagu pulang dan meminta anak untuk berdoa untuk pulang dan mengucapkan salam.

\section{Observasi}

Kegiatan yang dilakukan adalah mencatat semua peristiwa yang terjadi yang dialami anak didik, situasi dan kondisi belajar anak berdasarkan lembar observasi yang dibuat. Guru bercerita pada anak sesuai gambar yang ditunjukan, guru mengulang berkali-kali sampai anak paham, serta semua anak diminta untuk bercerita sesuai gambar yang ada. Pada langkah ini guru melakukannya dalam kategori baik karena guru berulang-ulang disaat mengucapkan kata yang ada dalam buku cerita bergambar memperlihatkan gambarnya sehingga anak terlihat tenang memperhatikan penjelasan gurunya. 
Hasil Penelitian Siklus I

Hasil yang diperoleh peneliti mengenai kemampuan berkomunikasi anak melalui metode cerita bergambar dinilai berdasarkan indikator penilaian.

Tabel 3

Penilaian Hasil Belajar Siklus I

\begin{tabular}{|c|c|c|c|c|c|c|}
\hline \multirow[t]{2}{*}{ No } & \multirow[t]{2}{*}{ Nama } & \multicolumn{2}{|c|}{$\begin{array}{c}\text { Hasil } \\
\text { Belajar }\end{array}$} & \multirow[t]{2}{*}{ Skor } & \multicolumn{2}{|c|}{ Ket } \\
\hline & & 1 & 2 & & $\mathbf{T}$ & BT \\
\hline 1 & AN & $\sqrt{ }$ & & 77 & $\sqrt{ }$ & \\
\hline 2 & $\mathrm{AB}$ & & $\sqrt{ }$ & 68 & & $\sqrt{ }$ \\
\hline 3 & $\mathrm{BN}$ & $\sqrt{ }$ & & 80 & $\sqrt{ }$ & \\
\hline 4 & $\mathrm{BU}$ & $\sqrt{ }$ & & 95 & $\sqrt{ }$ & \\
\hline 5 & DM & $\sqrt{ }$ & & 88 & $\sqrt{ }$ & \\
\hline 6 & ES & $\sqrt{ }$ & & 90 & $\sqrt{ }$ & \\
\hline 7 & GM & $\sqrt{ }$ & & 90 & $\sqrt{ }$ & \\
\hline 8 & MY & $\sqrt{ }$ & & 90 & $\sqrt{ }$ & \\
\hline 9 & MS & $\sqrt{ }$ & & 90 & $\sqrt{ }$ & \\
\hline 10 & SB & & $\sqrt{ }$ & 68 & & $\sqrt{ }$ \\
\hline 11 & SA & & $\sqrt{ }$ & 65 & & $\sqrt{ }$ \\
\hline 12 & VS & & $\sqrt{ }$ & 60 & & $\sqrt{ }$ \\
\hline 13 & YF & $\sqrt{ }$ & & 70 & $\sqrt{ }$ & \\
\hline 14 & YN & & $\sqrt{ }$ & 65 & & $\sqrt{ }$ \\
\hline 15 & FB & & $\sqrt{ }$ & 68 & & $\sqrt{ }$ \\
\hline 16 & SB & & $\sqrt{ }$ & 60 & & $\sqrt{ }$ \\
\hline 17 & $\mathrm{AH}$ & & $\sqrt{ }$ & 67 & & $\sqrt{ }$ \\
\hline 18 & DP & $\sqrt{ }$ & & & $\sqrt{ }$ & \\
\hline 19 & EN & $\sqrt{ }$ & & & $\sqrt{ }$ & \\
\hline \multicolumn{4}{|c|}{ Jumlah } & 1.446 & 11 & 8 \\
\hline \multicolumn{4}{|c|}{ Rata-rata } & 76.10 & & \\
\hline \multicolumn{4}{|c|}{ Persentase (\%) } & & 57.89 & 42.11 \\
\hline
\end{tabular}

Keterangan tabel:

$* \mathrm{BT}=$ Belum Tuntas, $\mathrm{T}=$ Tuntas

Angka pada kolom hasil belajar

a. Anak mampu bercerita dengan menggunakan artikulasi kata,intonasi dan mimik yang tepat

b. Anak masih di bantu oleh pendidik (peneliti) dalam bercerita,

Berdasarkan hasil penilaian siklus I maka maka dilihat bahwa anak (siswa) yang dapat mencapai kriteria ketuntasan minimum (KKM) berjumlah 11 orang sedangkana anak (siswa) yang belum mencapai kriteria ketuntasan minimum (KKM) berjumlah 8 orang, sehingga penelitian ini berlanjut ke siklus II.
Tabel 4

Hasil Observasi Siklus I

\begin{tabular}{|c|c|c|c|c|c|c|c|c|c|c|c|c|}
\hline \multirow[t]{2}{*}{$\begin{array}{l}\text { Na } \\
\text { ma }\end{array}$} & \multicolumn{3}{|c|}{$\begin{array}{c}\text { Bicara } \\
\text { mengg } \\
\text { unakan } \\
\text { artikul } \\
\text { asi } \\
\text { yang } \\
\text { jelas }\end{array}$} & \multicolumn{3}{|c|}{$\begin{array}{c}\text { Bicara } \\
\text { mengg } \\
\text { unakan } \\
\text { intonas } \\
\text { i yang } \\
\text { tepat }\end{array}$} & \multicolumn{3}{|c|}{$\begin{array}{c}\text { Bicara } \\
\text { menggu } \\
\text { nakan } \\
\text { mimik } \\
\text { yang } \\
\text { benar }\end{array}$} & \multirow[t]{2}{*}{$\begin{array}{l}\text { Sk } \\
\text { or }\end{array}$} & \multicolumn{2}{|c|}{ Ket } \\
\hline & 3 & 2 & 1 & 3 & 2 & 1 & 3 & 2 & 1 & & $\mathbf{T}$ & BT \\
\hline AN & & $\sqrt{1}$ & & & $\sqrt{1}$ & & & $\sqrt{1}$ & & 77 & $\sqrt{ }$ & \\
\hline $\mathrm{AB}$ & & $\sqrt{1}$ & & & $\sqrt{1}$ & & & & $\sqrt{ }$ & 68 & & $\sqrt{ }$ \\
\hline $\mathrm{BN}$ & $\sqrt{ }$ & & & & $\sqrt{1}$ & & $\sqrt{ }$ & & & 80 & $\sqrt{ }$ & \\
\hline $\mathrm{BU}$ & $\sqrt{1}$ & & & $\sqrt{ }$ & & & $\sqrt{ }$ & & & 95 & $\sqrt{ }$ & \\
\hline $\mathrm{DM}$ & $\sqrt{1}$ & & & $\sqrt{1}$ & & & $\sqrt{ }$ & & & 88 & $\sqrt{ }$ & \\
\hline ES & $\sqrt{1}$ & & & $\sqrt{1}$ & & & $\sqrt{ }$ & & & 90 & $\sqrt{ }$ & \\
\hline GM & $\sqrt{1}$ & & & $\sqrt{1}$ & & & $\sqrt{ }$ & & & 90 & $\sqrt{ }$ & \\
\hline MY & $\sqrt{1}$ & & & $\sqrt{1}$ & & & $\sqrt{ }$ & & & 90 & $\sqrt{ }$ & \\
\hline MS & $\sqrt{1}$ & & & $\sqrt{1}$ & & & $\sqrt{ }$ & & & 90 & $\sqrt{ }$ & \\
\hline SB & & $\sqrt{ }$ & & & $\sqrt{1}$ & & & & $\sqrt{ }$ & 68 & & $\sqrt{ }$ \\
\hline SA & & $\sqrt{1}$ & & & & $\sqrt{ }$ & & $\sqrt{1}$ & & 65 & & $\sqrt{ }$ \\
\hline $\mathrm{VS}$ & & $\sqrt{1}$ & & & $\sqrt{1}$ & & & & $\sqrt{ }$ & 60 & & $\sqrt{ }$ \\
\hline YF & & $\sqrt{1}$ & & & $\sqrt{1}$ & & & $\sqrt{1}$ & & 70 & $\sqrt{ }$ & \\
\hline YN & & & $\sqrt{ }$ & & & $\sqrt{ }$ & & & $\sqrt{ }$ & 65 & & $\sqrt{ }$ \\
\hline FB & & & $\sqrt{ }$ & & & $\sqrt{ }$ & & & $\sqrt{ }$ & 58 & & $\sqrt{ }$ \\
\hline SB & & $\sqrt{1}$ & & & $\sqrt{ }$ & & & & $\sqrt{ }$ & 60 & & $\sqrt{ }$ \\
\hline $\mathrm{AH}$ & & $\sqrt{1}$ & & & $\sqrt{1}$ & & & & $\sqrt{ }$ & 67 & & $\sqrt{ }$ \\
\hline $\mathrm{DP}$ & & $\sqrt{ }$ & & $\sqrt{1}$ & $\sqrt{1}$ & & & $\sqrt{1}$ & & 75 & $\sqrt{ }$ & \\
\hline EN & $\sqrt{ }$ & & & $\sqrt{1}$ & & & & $\sqrt{1}$ & & 90 & $\sqrt{ }$ & \\
\hline \multicolumn{10}{|c|}{ Jumlah } & 1.446 & 11 & 8 \\
\hline \multicolumn{10}{|c|}{ Rata- rata } & 76,10 & & \\
\hline \multicolumn{10}{|c|}{ Persentase (\%) } & & $\begin{array}{l}57, \\
89\end{array}$ & $\begin{array}{c}42, \\
11\end{array}$ \\
\hline
\end{tabular}

Keterangan table :

$3=$ Sangat Baik $2=$ Cukup Baik $1=$ Kurang Baik

$\mathrm{T}=$ Tuntas $\mathrm{BT}=$ Belum Tuntas

\section{Refleksi}

Pada tahap ini peneliti bersama observer dan guru memberikan tanggapan atau masukan bagi peneliti terkait dengan jalannya proses penelitian serta respon anak dalam mengikuti kegiatan pembelajaran yang telah diterapkan. Dari hasil refleksi yang dilakukan diketahui bahwa kebanyakan anak memberi respon positif dan dapat berpartisipasi dalam kegiatan pembelajaran, namun mereka lebih bersikap aktif ketika kegiatan pembelajaran mulai menggunakan media gambar. Selain itu, dilihat dari hasil penilaian tes hasi belajar kebanyakan anak belum mampu bercerita sendiri, dan masih di bantu oleh peneliti ataupun guru.

Dari hasil penelitian siklus I dapat diberikan penilaian beberapa indikator total 
keseluruhan hasil yang didapatkan yaitu 57,89\% (11 anak) yang sudah berhasil dan dari perolehan nilai yang dipaparkan maka peneliti menyatakan bahwa kriteria keberhasilan belum mencapai yang diharapkan minimal $>70 \%$. Presentase ketuntasan yang belum mencapai kriteria $>70 \%$ ini disebabkan anak belum mampu berkomunikasi dengan baik sesuai dengan kriteria yang ditetapkan. Dengan demikian hipotesis belum dapat diterima dalam pelaksanaan siklus I dan melanjutkan ke siklus II.

\section{Deskripsi Hasil Data Penelitian Siklus II}

Siklus II dilakukan berdasar dari hasil siklus I belum mencapai kriteria keberhasilan minimal $>70 \%$ yang ditetapkan peneliti. Siklus ini masih sama dengan siklus I yakni dimulai dari perencanaan, pelaksanaan, observasi dan refleksi.

\section{Perencanaan}

Berdasarkan hasil refleksi pada siklus I maka peneliti lebih memotivasi anak yang belum tuntas untuk lebih bersungguh-sungguh mengikuti kegiatan pembelajaran pada siklus II ini. Sebelum melakukan kegiatan siklus II peneliti bersama guru melakukan refleksi pada siklus I dengan tujuan agar pembelajaran pada siklus II lebih membangkitkan semangat anak yang belum tuntas sesuai KKM, dengan menyiapkan rencana perbaikan pembelajaran berupa RPPH tentang tema pembelajaran sebagai bahan acuan menyiapkan media yang akan digunakan seperti buku cerita bergambar, membuat lembar observasi untuk melihat kemampuan berkomunikasi anak pada saat proses pembelajaran berlangsung.

\section{Pelaksanaan}

Pada tahap ini kegiatan pembelajaran masih sama dengan yang terjadi pada siklus I yakni melalui 3 kegiatan:

Kegiatan Awal : anak-anak berbaris di halaman sebelum masuk kelas, setelah masuk ke dalam kelas, guru meminta salah satu anak untuk memberi salam dan berdoa. Kemudian guru memanggil masing-masing anak dan mengisi daftar absensi anak. Guru mengajak anak bernyanyi sesuai tema yang akan diajarkan. Guru memberikan kesempatan kepada anak untuk bertanya.

Kegiatan Inti : kegiatan yang pertama dilakukan guru kurang lebih sama dengan pertemuan-pertemuan sebelumnya ialah menyiapkan buku cerita bergambar sebagai bahan yang akan diajarkan kepada anak sebelum proses belajar mengajar dimulai dan memotivasi anak untuk tetap bersemangat dan aktif mengikuti kegiatan pembelajaran, setelah itu guru mengemukakan tema yang akan diajarkan yaitu tema alam semesta dan mengemukakan tujuan pembelajaran yang akan dicapai yaitu meningkatkan kemampuan berkomonikasi anak, setelah itu guru memperlihatkan buku gambar yang mempunyai gambar seperti matahari, bintang, bulan dan awan, kemudian anak diberikan kesempatan untuk bertanya da selanjutnya guru menceritakan kepada anak sesuai gambar yang ada. Setelah menceritakan, setiap anak diminta untuk menceritakan kembali apa yang disampaikan guru ataupun menceritakan pengalaman anak sesuai gambar yang dilihat.

Kegiatan Penutup : guru mengadakan tanya jawab tentang kegiatan yang telah dilakukan tadi, anak menyanyikan lagu pulang dan meminta anak untuk berdoa untuk pulang dan mengucapkan salam.

\section{Observasi}

Mencatat semua peristiwa yang terjadi yang dialami anak didik, situasi dan kondisi belajar anak berdasarkan lembar observasi yang dibuat. Guru bercerita pada anak sesuai gambar yang ditunjukan, guru mengulang berkali-kali sampai anak paham. Serta semua anak diminta untuk bercerita sesuai gambar yang ada. Pada langkah ini guru melakukannya dengan sangat baik karena guru selalu mengulang kata yang ada dalam buku cerita bergambar serta memperlihatkan gambar sehingga anak terlihat tenang memperhatikan penjelasan gurunya. 
Hasil Penilaian Siklus II

Hasil yang diperoleh peneliti mengenai kemampuan berkomunikasi anak melalui metode cerita bergambar dinilai berdasarkan indikator penilaian.

Tabel 5

Penilaian Hasil Belajar Siklus II

\begin{tabular}{|c|c|c|c|c|c|c|}
\hline \multirow{2}{*}{ No } & \multirow{2}{*}{ Nama } & \multicolumn{2}{|c|}{$\begin{array}{l}\text { Hasil } \\
\text { Belajar }\end{array}$} & \multirow{2}{*}{ Skor } & \multicolumn{2}{|c|}{ Keterangan } \\
\hline & & 1 & 2 & & $\mathbf{T}$ & BT \\
\hline 1 & $\mathrm{AN}$ & $\sqrt{ }$ & & 100 & $\sqrt{ }$ & \\
\hline 2 & $\mathrm{AB}$ & $\sqrt{ }$ & & 95 & $\sqrt{ }$ & \\
\hline 3 & $\mathrm{BN}$ & $\sqrt{ }$ & & 80 & $\sqrt{ }$ & \\
\hline 4 & $\mathrm{BU}$ & $\sqrt{ }$ & & 95 & $\sqrt{ }$ & \\
\hline 5 & $\mathrm{DM}$ & $\sqrt{ }$ & & 88 & $\sqrt{ }$ & \\
\hline 6 & ES & $\sqrt{ }$ & & 90 & $\sqrt{ }$ & \\
\hline 7 & GM & $\sqrt{ }$ & & 90 & $\sqrt{ }$ & \\
\hline 8 & MY & $\sqrt{ }$ & & 90 & $\sqrt{ }$ & \\
\hline 9 & MS & $\sqrt{ }$ & & 90 & $\sqrt{ }$ & \\
\hline 10 & SB & $\sqrt{ }$ & & 90 & $\sqrt{ }$ & \\
\hline 11 & SA & $\sqrt{ }$ & & 90 & $\sqrt{ }$ & \\
\hline 12 & VS & $\sqrt{ }$ & & 85 & $\sqrt{ }$ & \\
\hline 13 & YF & $\sqrt{ }$ & & 90 & $\sqrt{ }$ & \\
\hline 14 & YN & $\sqrt{ }$ & & 85 & $\sqrt{ }$ & \\
\hline 15 & FB & $\sqrt{ }$ & & 80 & $\sqrt{ }$ & \\
\hline 16 & SB & $\sqrt{ }$ & & 85 & $\sqrt{ }$ & \\
\hline 17 & $\mathrm{AH}$ & $\sqrt{ }$ & & 85 & $\sqrt{ }$ & \\
\hline 18 & DP & $\sqrt{ }$ & & 100 & $\sqrt{ }$ & \\
\hline 19 & EN & $\sqrt{ }$ & & 100 & $\sqrt{ }$ & \\
\hline \multicolumn{4}{|c|}{ Jumlah } & 1708 & 19 & \\
\hline \multicolumn{4}{|c|}{ Rata-rata } & 89.89 & & \\
\hline \multicolumn{4}{|c|}{ Persentase (\%) } & & 100 & \\
\hline
\end{tabular}

Berdasarkan hasil penilaian siklus II, maka dilihat bahwa semua anak mencapai kriteria ketuntasan minimum, sehingga penelitian ini tidak berlanjut ke siklus berikutnya.

Tabel 6

Obsevasi Hasil Penelitian Siklus II

\begin{tabular}{|c|c|c|c|c|c|c|c|c|c|c|c|c|}
\hline \multirow[t]{2}{*}{$\begin{array}{l}\mathrm{Na} \\
\mathrm{ma}\end{array}$} & \multicolumn{3}{|c|}{$\begin{array}{c}\text { Bicara } \\
\text { mengg } \\
\text { unaka } \\
\text { n } \\
\text { artikul } \\
\text { asi } \\
\text { yang } \\
\text { jelas }\end{array}$} & \multicolumn{3}{|c|}{$\begin{array}{c}\text { Bicara } \\
\text { menggu } \\
\text { nakan } \\
\text { intonasi } \\
\text { yang } \\
\text { tepat }\end{array}$} & \multicolumn{3}{|c|}{$\begin{array}{c}\text { icara } \\
\text { menggu } \\
\text { nakan } \\
\text { mimik } \\
\text { yang } \\
\text { benar }\end{array}$} & \multirow[t]{2}{*}{ Skor } & \multicolumn{2}{|c|}{ Ket } \\
\hline & 3 & 2 & 1 & 3 & 2 & 1 & 3 & 2 & 1 & & $\mathbf{T}$ & $\begin{array}{l}\mathbf{B} \\
\mathbf{T}\end{array}$ \\
\hline AN & $\sqrt{1}$ & & & $\sqrt{ }$ & & & $\sqrt{ }$ & & & 100 & $\sqrt{ }$ & \\
\hline $\mathrm{AB}$ & $\sqrt{ }$ & & & $\sqrt{ }$ & & & $\sqrt{ }$ & & & 95 & $\sqrt{ }$ & \\
\hline $\mathrm{BN}$ & $\sqrt{ }$ & & & $\sqrt{ }$ & & & $\sqrt{ }$ & & & 80 & $\sqrt{ }$ & \\
\hline $\mathrm{BU}$ & $\sqrt{1}$ & & & $\sqrt{1}$ & & & $\sqrt{ }$ & & & 95 & $\sqrt{ }$ & \\
\hline $\mathrm{DM}$ & $\sqrt{ }$ & & & $\sqrt{ }$ & & & $\sqrt{ }$ & & & 88 & $\sqrt{ }$ & \\
\hline
\end{tabular}

\begin{tabular}{|c|c|c|c|c|c|c|}
\hline ES & $\sqrt{ }$ & $\sqrt{ }$ & $\sqrt{ }$ & 90 & $\sqrt{ }$ & \\
\hline GM & $\sqrt{ }$ & $\sqrt{1}$ & $\sqrt{ }$ & 90 & $\sqrt{ }$ & \\
\hline MY & $\sqrt{ }$ & $\sqrt{ }$ & $\sqrt{ }$ & 90 & $\sqrt{ }$ & \\
\hline MS & $\sqrt{1}$ & $\sqrt{1}$ & $\sqrt{ }$ & 90 & $\sqrt{ }$ & \\
\hline SB & $\sqrt{ }$ & $\sqrt{1}$ & $\sqrt{ }$ & 90 & $\sqrt{ }$ & \\
\hline SA & $\sqrt{1}$ & $\sqrt{1}$ & $\sqrt{ }$ & 90 & $\sqrt{ }$ & \\
\hline VS & $\sqrt{1}$ & $\sqrt{1}$ & $\sqrt{ }$ & 85 & $\sqrt{ }$ & \\
\hline YF & $\sqrt{ }$ & $\sqrt{b}$ & $\sqrt{ }$ & 90 & $\sqrt{ }$ & \\
\hline YN & $\sqrt{1}$ & $\sqrt{1}$ & $\sqrt{ }$ & 85 & $\sqrt{ }$ & \\
\hline FB & $\sqrt{ }$ & $\sqrt{ }$ & $\sqrt{ }$ & 80 & $\sqrt{ }$ & \\
\hline SB & $\sqrt{ }$ & $\sqrt{1}$ & $\sqrt{1}$ & 85 & $\sqrt{ }$ & \\
\hline $\mathrm{AH}$ & $\sqrt{ }$ & $\sqrt{1}$ & $\sqrt{1}$ & 85 & $\sqrt{ }$ & \\
\hline DP & $\sqrt{ }$ & $\sqrt{ }$ & $\sqrt{ }$ & 100 & $\sqrt{ }$ & \\
\hline EN & $\sqrt{ }$ & $\sqrt{1}$ & $\sqrt{1}$ & 100 & $\sqrt{ }$ & \\
\hline \multicolumn{4}{|c|}{ Jumlah } & 1708 & 19 & 0 \\
\hline \multicolumn{4}{|c|}{ Rata- rata } & 89,89 & & \\
\hline & & ntas & & & 100 & 0 \\
\hline
\end{tabular}

Keterangan tabel:

$3=$ Sangat Baik 2 = Cukup Baik $1=$ Kurang Baik

$\mathrm{T}=$ Tuntas $\mathrm{BT}=$ Belum Tuntas

Berdasarkan hail pengelolahan data pada tabel 6. tentang indikator anak mampu bercerita dengan buku cerita bergambar dan menigkatkan kemampuan berkomunikasi anak. Sesuai hasil yang diperoleh oleh observer, maka pada pembelajaran siklus II dinyatakan tuntas $100 \%$.

\section{$5 \quad$ Refleksi}

Tahap pelaksanaan sudah bagus sehingga penelitian yang dilaksanakan pada pertemuan II lebih meningkat dari hasil pertemuan I. Guru telah berusaha secara maksimal dalam membimbing dan mengarahkan anak didik yang mengalami kesulitan dalam melakukan kegiatan yang berhubungan dengan penelitian. Pada observasi guru telah berusaha semaksimal mungkin dalam mengamati keseluruhan anak didik selama kegiatan penelitian berlangsung.

\section{Pembahasan}

Pengambilan nilai atau hasil belajar anak (siswa) dilakukan untuk mengetahui sejauh mana tingkat pemahaman dan keberhasilan anak (siswa) dalam memahami materi tentang metode cerita bergambar. Dari data yang diperoleh peneliti, berdasarkan nilai 
pra siklus anak memiliki persentase ketuntasan belajar siswa masih sangat rendah yakni $31,57 \%$ dari jumlah 19 anak dan jumlah siswa yang tuntas 8 anak.

Siklus I dilaksanakan dalam dua kali pertemuan kemudian pada pertemuan ketiga dilakukan tes hasil belajar untuk menilai ketuntasan belajar anak (siswa). Siklus I ini terdiri dari empat tahap yaitu tahap perencanaan, tahap pelaksanaan, tahap evaluasi, dan tahap refleksi. Dari data yang diperoleh peneliti dapat dilihat bahwa anak yang tuntas dalam penilaian tes hasil belajar siklus I berjumlah 11 orang dan mencapai pesentase $57,89 \%$. Persentase ini mengalami peningkatan sebesar $26,32 \%$ dari nilai pra siklus. Nilai tertinggi dari tes hasil belajar ini adalah 90 dan nilai terendah adalah 58, sedangkan anak yang belum tuntas berjumlah 8 orang dan mencapai persentase $42,11 \%$.

Siklus II merupakan kelanjutan dari siklus I. Jika pada siklus I peningkatan kemampuan anak secara klasikal dan individu belum tercapai, maka siklus II perlu dilakukan untuk meningkatkan kemampuan anak dalam belajar. Sedangkan jika pada siklus I ketuntasan belajar klasikal dan individu telah tercapai, maka siklus II dilakukan guna memberi penguatan atas hasil yang dicapai pada siklus I namun tetap dalam upaya meningkatkan kemampuan dan hasil belajar anak (siswa). Siklus II ini juga dilaksanakan dalam dua kali pertemuan kemudian pada pertemuan ketiga dilaksanakan tes hasil belajar. Pada siklus ini juga dilakukan dalam empat tahap yaitu tahap perencanaan, tahap pelaksanaan, tahap evaluasi dan tahap refleksi. Dari data yang diperoleh dapat dilihat bahwa anak yang tuntas dalam penilaian tes hasil belajar siklus II berjumlah 19 orang dan mencapai persentase $100 \%$. Persentase ini mengalami peningkatan sebesar $42,11 \%$ dari pelaksanaan silkus I. Nilai tertinggi dari unjuk kerja ini adalah 100 dan nilai terendah adalah 80 .

Dari hasil penelitian ini diketahui bahwa penerapan metode cerita bergambar dapat meningkatkan kemampuan anak dalam meningkatan kemampuan berkomunikasi di PAUD Gemilang Kota Kupang.

\section{SIMPULAN}

Berdasarkan hasil penelitian dan pembahasan di atas dapat diambil kesimpulan bahwa menggunakan metode cerita bergambar dapat meningkatkan kemampuan berkomunikasi anak di PAUD Gemilang Kota Kupang.

\section{Saran}

Berdasarkan apa yang telah disampaikan maka disarankan hal-hal sebagai berikut:

1. Kepada guru PAUD agar memahami berbagai macam metode dalam pembelajaran agar suasane belajar lebih bervariatif.

2. Kepada pihak sekolah disarankan agar dapat memberikan masukan dalam meningkatkan kualitas pembelajaran khususnya penggunaan media gambar untuk meningkatkan kemampuan anak.

3. Kepada anak yang menjadi sasaran dalam penelitian ini agar dapat mengembangkan kemampuan anak, dapat memberikan kesempatan pada anak untuk ikut serta dalam proses belajar mengajar.

\section{DAFTAR PUSTAKA}

Arikunto, S. 2006. Penelitian Tindakan Kelas. Jakarta : PT Bumi Aksara.

Hidayati, S. 2014. Upaya Meningkatkan Kemampuan Bahasa Verbal Anak Melalui Metode Bercerita Dengan Gambar Seri Di RA Perwanida Grabag Magelang Kelompok A Kelas MA'WA. Skripsi tidak diterbitkan. Yogyakarta : Fakultas Ilmu Tarbiyah dan Keguruan. Universitas Islam Negeri Sunan Kalijaga Yogyakarta.

Hurlock, E. 1978. Perkembangan Anak Jilid I. (Alih Bahasa: Agus Dharma). Jakarta: Erlangga.

Rolina, N. 2010. Media dan Sumber Belajar. Dalam Buku 2 : Pendidikan Guru Taman Kanak-kanak. Yogyakarta: 
Panitia Sertifikasi Guru (PSG) Rayon 11, Kementerian Pendidikan Nasional, UNY.

Suyanto, S. 2005. Dasar-dasar Pendidikan Anak Usia Dini . Yogyakarta : Hikayat Publising.

Suhartono. 2005. Pengembangan Keterampilan Bicara Anak Usia Dini. Jakarta : Departemen Pendidikan Nasional, Direktorat Jenderal Pendidikan Tinggi, Direktorat Pembinaan Pendidikan Tenaga Kependidikan dan Ketenagaan Perguruan Tinggi. 